\title{
Crab bioturbation significantly alters sediment microbial composition and function in an intertidal marsh
}

\author{
Chuanjing $\mathrm{Wu}^{\mathrm{a}}$, Haitao $\mathrm{Wu}^{\mathrm{a}}{ }^{\text {,* }}$, Dandan Liu ${ }^{\mathrm{a}}$, Guangxuan Han ${ }^{\mathrm{b}}$, Panpan Zhao ${ }^{\mathrm{c}}$, Yujuan Kang ${ }^{\mathrm{a}}$ \\ ${ }^{\text {a }}$ Key Laboratory of Wetland Ecology and Environment, Northeast Institute of Geography and Agroecology, Chinese Academy of Sciences, Changchun, Jilin, 130012, \\ China \\ ${ }^{\mathrm{b}}$ Yantai Institute of Coastal Zone Research, Chinese Academy of Sciences, Yantai, 264003, China \\ ${ }^{\mathrm{c}}$ State Key Laboratory of Biocontrol, School of Life Sciences, Sun Yat-sen University, Guangzhou, 510275, China
}

\section{A R T I C L E I N F O}

\section{Keywords:}

Ecosystem engineer

Function prediction

Network analysis

Soil microbes

Yellow river delta

\begin{abstract}
A B S T R A C T
Crabs are among the most important benthos in intertidal marshes. Numerous studies have shown that they can influence soil properties and soil-surface water exchange through bioturbation. However, little is still known about the effects of crab burrows on sediment microbes. In this study, we examined the effects of crab burrows on the community structure and interaction pattern of soil microbes in sediments in an intertidal marsh of the Yellow River Delta, north China using high-throughput sequencing and co-occurrence network analyses. Results showed that crab bioturbations altered soil microbial community composition both within the fungal and bacterial communities. Network analyses results indicated that the modularity of fungal networks decreased after crab bioturbation. Further, bacterial and fungal functional predictions indicated the relative abundances were significantly lower for fungal saprotrophs and saprotroph-pathotrophs in the soil mound sediment, while significantly higher for bacterial chemoheterotrophs and aerobic chemoheterotrophic in the burrow wall sediment. Our results demonstrate that crab bioturbation can modify the microbial community structure and function, and thus nutrient cycling through degradation of organic matter, a key ecosystem processes in intertidal marsh.
\end{abstract}

\section{Introduction}

Ecosystem engineers are that organisms can modulate the availability of resources for other species through physical structures, physiology, and behavioral activity (Jones, 1995). Studies about soil ecosystem engineers (e.g. earthworm, ant) in terrestrial ecosystems have revealed the impacts on soil structure, soil heterogeneity, soil nutrient availability, gas diffusion and maintaining species diversity by their burrowing and foraging (Wolters, 2000; Wu et al., 2013; Bertrand et al., 2015; Wu et al., 2015 a,b). Benthos can alter sediment structures by digging burrows (Kristensen et al., 2008). In addition, they can change the chemical properties of sediments by foraging and excretion (Wieltschnig et al., 2008). There has been growing evidence that benthic invertebrates in aquatic sediments can also increase microbial activity and alter nutrient cycling (Wang et al., 2010; Luo and Gu, 2018).

Benthic invertebrates affect the energy flow and nutrient cycle of estuary wetland ecosystems. They achieve functions through physiological activities, such as burrowing, excretion, and bioirrigation, which strongly affect the biogeochemical cycle processes of wetlands, particularly carbon (C) and nitrogen (N) cycling in sediments (Lohrer et al., 2004; Eldridge et al., 2015). Crabs are one of the most abundant benthos in coastal wetlands. They can directly affect soil properties and ground water-surface water exchange through burrows (Stahl et al., 2014; Hu et al., 2015; Xiao et al., 2019). Studies have found that burrowing crabs are strongly associated with mangrove trees and the existence of their burrows counteracts the reduced redox potential in mangrove sediments (Robertson and Daniel, 1989; Gillis et al., 2019). Ferreira et al. (2007) revealed that lowest pyrite-Fe, degree of pyritization and acid volatile sulfide values in summer are related to increased crab activity such as foraging and reproduction. Most of these studies focus on the effects of bioturbation on nutrient cycling and plant growth ( $\mathrm{He}$ and Silliman, 2016; Luo and Gu, 2018; Gutiérrez et al., 2018). However, little is known about the effects of crab bioturbation on microbial community composition and diversity. Bioturbation increases oxygen penetration, alters the physical and chemical conditions in sediments, controls the composition of microbial communities, alters microbial activity and

\footnotetext{
* Corresponding author. Chinese Academy of Sciences, Changchun, Jilin, 130012, China.

E-mail address: wuhaitao@iga.ac.cn (H. Wu).
} 

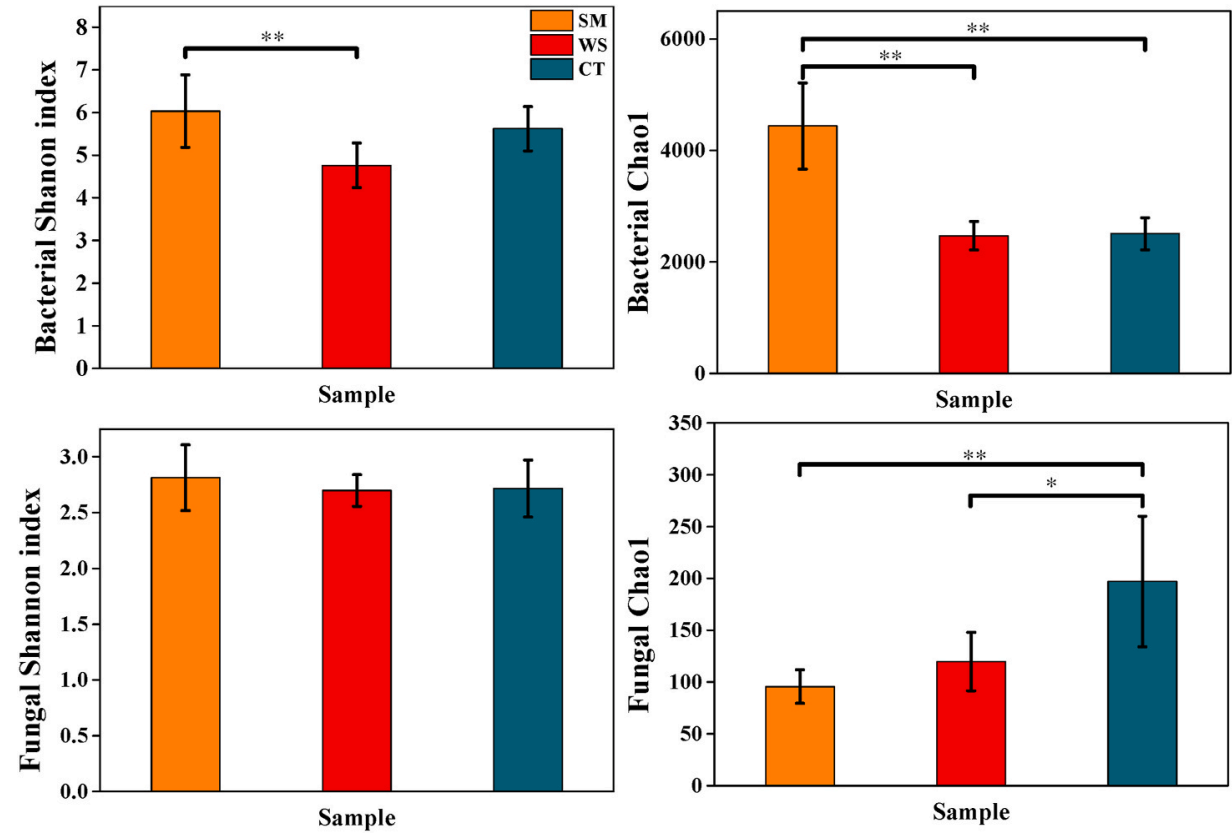

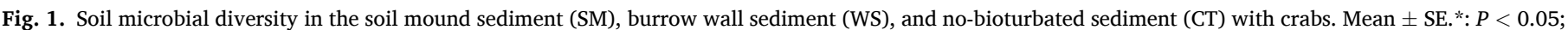
$* *: P<0.01$.

benthic metabolism, and the burrowing activity can create habitats for other small organisms (Derksen et al., 2019).

Both bacteria and fungi are important components of soil microbial assemblages and provide important ecological functions, including nutrient cycling and interactions with vegetation (Falkowski et al., 2008). Soil carbon is the energy source on which microbes depend (Delgado-Baquerizo et al., 2016). It is generally believed that fungi and bacteria have different substrate preferences. Fungi tend to decompose recalcitrant carbon, whereas bacteria tend to assimilate soil labile C (Myers et al., 2001; Courty et al., 2010). Studies have shown that soil microbial community structures are affected by environmental factors such as temperature and precipitation (Guo et al., 2018; Ochoa-Hueso et al., 2018). Soil pH is an important environmental factor to predict the response of microbial $\alpha$ diversity to global changes due to physiological constraints on microorganisms (Rousk et al., 2010). Compared with abiotic factors, biotic factors have been less studied in regard to the influence of microbes.

In recent years, the development of high-throughput sequencing technology has enhanced soil microbial studies (Bates et al., 2013). Further, the application of biological network analysis is useful to study interactions of microbes. This study applied high-throughput sequencing technology to study soil microbes that are affected by crab bioturbation. The bacterial and fungal communities of the crab burrows were described, and their microbial networks were analyzed. The effects of crabs on the composition of, and interactions among soil microbial communities were evaluated. Our hypotheses were as follows: (1) the structure of bacterial and fungal communities change during bioturbation; and (2) crab burrows change the microbial community structure, and thereby the interaction pattern of the entire microbial network; and (3) the functions of bacteria and fungi in such ecosystems are affected by crab bioturbation.

\section{Materials and methods}

\subsection{Study area and sample collection}

The study site was the Yellow River Delta coastal wetlands $\left(37^{\circ} 35^{\prime}\right.$ $38^{\circ} 12^{\prime} \mathrm{N}, 118^{\circ} 33^{\prime}-119^{\circ} 20^{\prime} \mathrm{E}, 0-15 \mathrm{~m}$ above the sea level). It is a warm temperate continental monsoon climate with an average annual temperature of $11.7^{\circ} \mathrm{C}-12.6^{\circ} \mathrm{C}$, and annual precipitation of $551.6 \mathrm{~mm}$, $70 \%$ in summer. Rain and high temperatures typically occur during the same period. The main soil types in the study area are fluvo-aquic and saline soils. We randomly selected 6 active crab burrows (i.e. crabs were observed). We collected crab bioturbated soil samples from soil mound sediment (SM), burrow wall sediment (WS), and non-bioturbated sediment as the control (CT) ( $\mathrm{n}=6$ for each treatment, total of 18 replicates). We collect soil mound and burrow wall sediments to $5 \mathrm{~cm}$ depths. Non crab bioturbated sediment sampling depths were also $5 \mathrm{~cm}$. All sediment samples were stored on ice, and immediately transported to the laboratory.

\subsection{Soil DNA extraction, quantification, and Illumina MiSeq sequencing}

Total DNA was isolated from soil samples using the E.Z.N.A. ${ }^{\circledR}$ soil DNA Kit (Omega Bio-tek, Norcross, GA, USA) according to the manufacturer's instructions. The final DNA concentrations and purification were determined using a NanoDrop 2000 UV-vis spectrophotometer (Thermo Scientific, Wilmington, USA). The DNA quality was checked by $1 \%$ agarose gel electrophoresis. The V3-V4 hypervariable regions of the bacteria 16S rRNA gene were amplified with primers 338F (ACTCCTACGGGAGGCAGCAG) and 806R (GGACTACHVGGGTWTCTAAT), and for the ITS rRNA gene were amplified with primers ITS1F (CTTGGTCATTTAGAGGAAGTAA) and ITS2R (GCTGCGTTCTTCATCGATGC). Purified amplicons were pooled in equimolar concentrations, and then paired-end sequenced on an Illumina MiSeq platform (Illumina, San Diego, USA) in the Majorbio Bio-Pharm Technology Co. Ltd. (Shanghai, China) according to its standard protocols.

\subsection{Statistical and co-occurrence network analyses}

Raw FASTQ files were quality-filtered by Trimmomatic and merged by FLASH (Magoc and Salzberg, 2011) using the following criteria: (1) if the mean quality score $<20$, reads were truncated over a 50 bp sliding window, and reads shorter than $50 \mathrm{bp}$ were discarded after quality control; and (2) ambiguous characters were discarded. After chimeras and singletons were detected and removed, operational taxonomic units (OTUs) were clustered on the basis of $97 \%$ similarity with the USEARCH tool (v.7.0 http://drive5.com/uparse/) and classified using the SILVA 


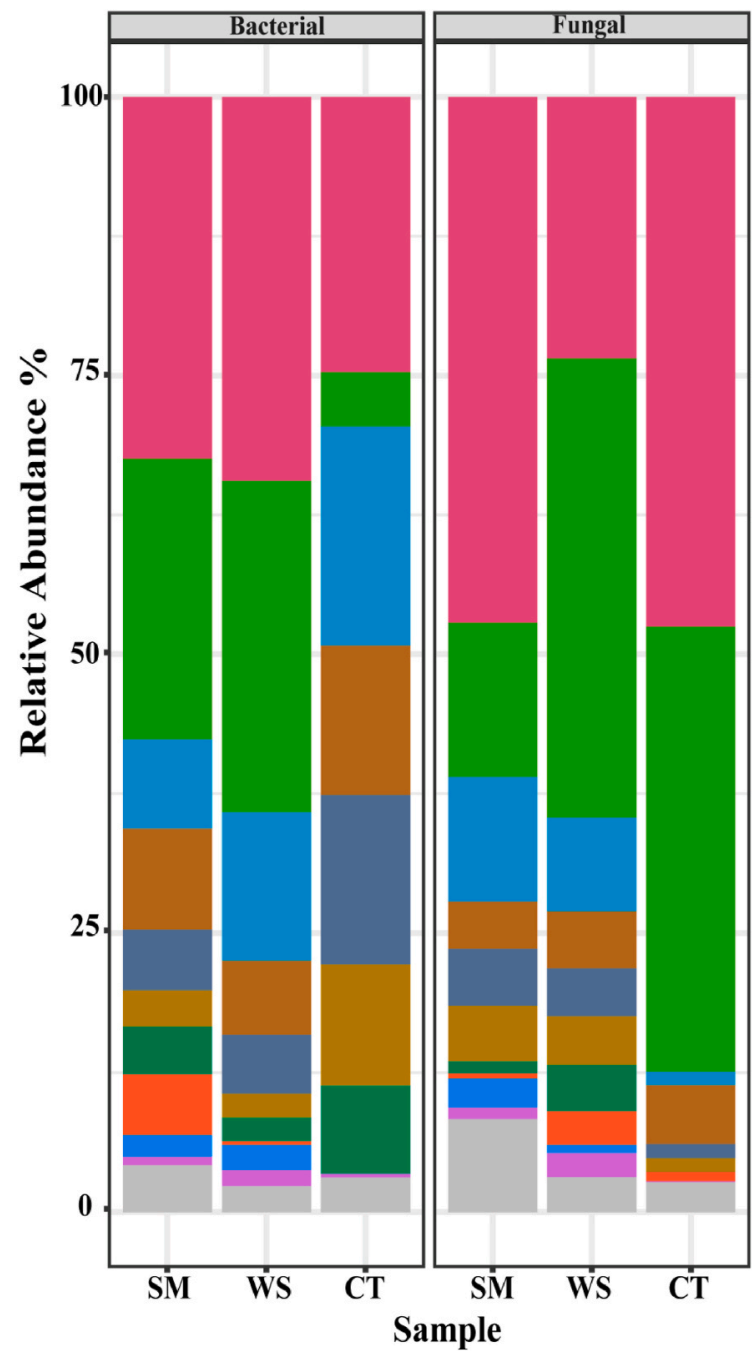

Bacterial Phylum

Proteobacteria

Bacteroidetes

Firmicutes

Chloroflexi

Actinobacteria

Gemmatimonadetes

Acidobacteria

Halanaerobiaeota

Epsilonbacteraeota

Deinococcus-Thermus

Others

Fungal Class

Sordariomycetes

Dothideomycetes

Agaricomycetes

Eurotiomycetes

unclassified_Fungi

Tremellomycetes

unclassified_Rozellomycota

unclassified_Chytridiomycota

Rozellomycotina_Incertae_sedis

Saccharomycetes

Others

Fig. 2. Soil microbial composition in the soil mound sediment (SM), burrow wall sediment (WS), and no-bioturbated sediment (CT).

database (Quast et al., 2013) for bacteria and the UNITE database (Abarenkov et al., 2010) for fungi. The functions of soil bacteria and fungi were separately identified using the Functional Annotation of Prokaryotic Taxa (FAPROTAX) (Louca et al., 2016) and FUNGuild (Nguyen et al., 2016).

The effects of crab bioturbation on the microbial community structure, diversity and function relative abundance were determined by contrasting the three soil treatments using one-way analysis of variance (ANOVA). Characterization of bacterial and fungal $\alpha$-diversity was achieved by applying the Chao 1 and Shannon indices. The effects of crab burrows on the soil microbial community were visualized using non-metric multidimensional scaling (NMDS) and assessed through a permutation multivariate analysis of variance (PERMANOVA). The Psych package in the R program (V.3.6.1) was used for co-occurrence network analyses. Only significant differences $(P<0.05)$, absolute correlation values $>0.8$, and relative abundance $>0.2 \%$ OTUs were considered for construction of the network. The networks were visualized using the interactive Gephi platform and the Fruchterman-Reingold layout algorithm.

\section{Result}

\subsection{Abundance and richness of microbial communities}

Sequencing results were clustered into 7999 bacterial and 1156 fungal OTUs, with a $97 \%$ identity threshold. For bacterial OTUs, A total of $112(1 \%)$ OTUs contributed $50 \%$ of the total bacterial OTU abundances. While for fungal OTUs, 12 (1\%) OTUs contributed $50 \%$ of the total fungal OTU abundances. Significant differences were noted in the bacterial $\alpha$-diversity between SM and WS. The bacterial Chao 1 index was significantly higher in mound sediments (SM) than in wall sediments (WS) or control sediments (CT) $(P<0.01)$. The fungal Chao 1 index of the CT was significantly higher than that of the SM or WS $(P<$ 0.01). In contrast, no significant differences were noted in the fungal Shannon index among the three different sample sources (Fig. 1).

\subsection{Taxonomic composition}

A total of 53 bacterial phyla and 13 fungal phyla were observed. The seven phyla of bacteria with higher relative abundance were Proteobacteria, Bacteroidetes, Firmicutes, Chloroflexi, Actinobacteria, Gemmatimonadetes, and Acidobacteria. The dominant bacterial phyla were Proteobacteria and Bacteroidetes in crab bioturbated sediment (SM, WS), representing $32.3 \%-35.1 \%$ and $21.1 \%-34.8 \%$, respectively (Fig. 2). The dominant bacterial phyla in non-bioturbated sediment were Proteobacteria and Firmicutes, representing 25.7\% and 10.6\%, respectively. Crab burrows also had a significant influence on specific taxa. The relative abundances were higher for Proteobacteria and Bacteroidetes while lower for Actinobacteria and Gemmatimonadetes in the two crab bioturbated sediment than in the non-bioturbated sediment. While the relative abundances of Actinobacteria and Gemmatimonadetes were lower in the bioturbated sediment than in the non-bioturbated sediment 

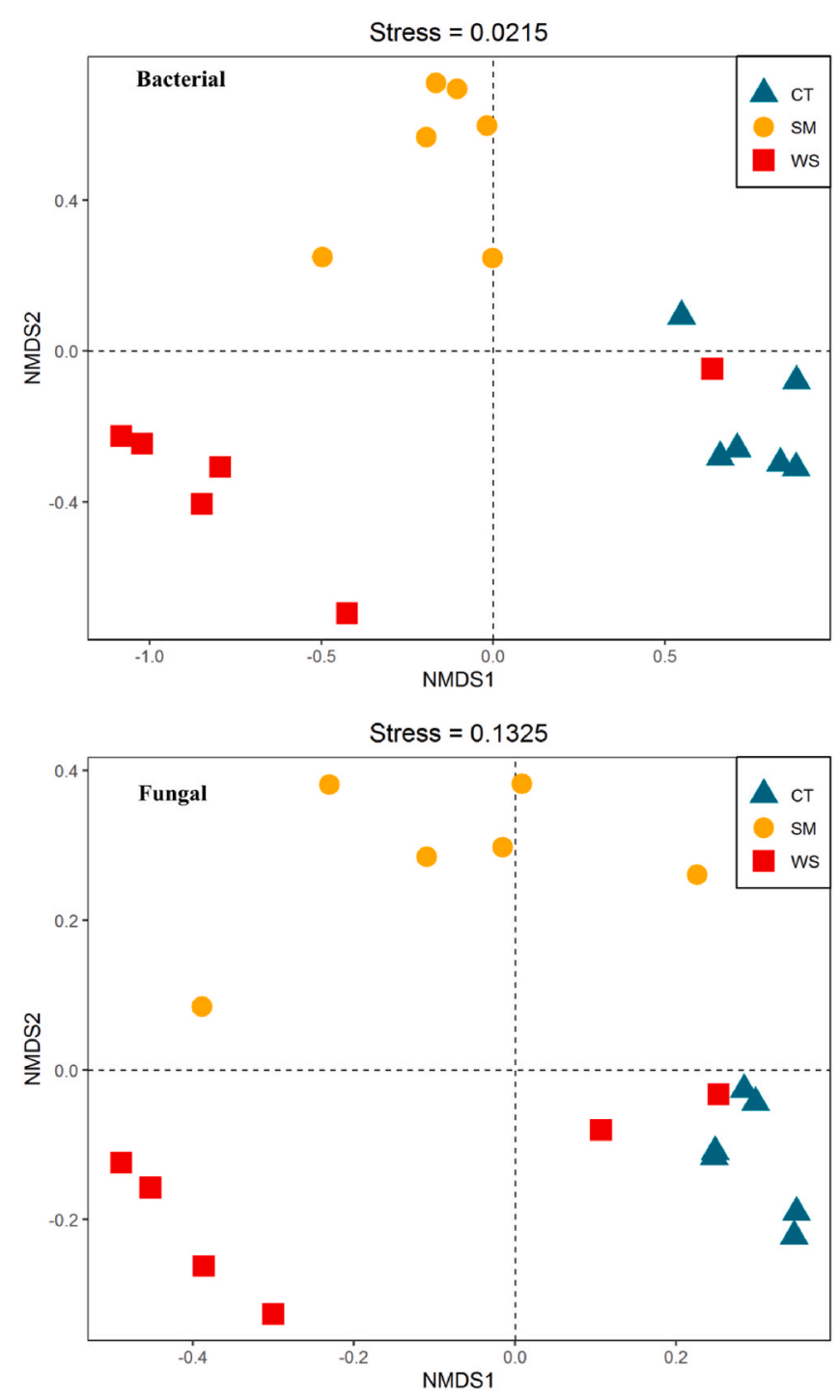

Fig. 3. Non-metric multidimensional scaling (NMDS) plot of bacterial and fungal community structures in the soil mound sediment (SM), burrow wall sediment (WS), and non-bioturbated sediment (CT) with crabs.

\section{Table 1}

Permutation multivariate analysis of variance (PERMANOVA) on the effects of crab bioturbation on bacterial and fungal assemblages in sediment. $\mathrm{R}^{2}$ shows the percentage of variation attributed to the treatment; ${ }^{* *}: P<0.01$. SM: soil mound sediment, WS: burrow wall sediment, and CT: no-bioturbated sediment.

\begin{tabular}{llllll}
\hline Disturbance & \multicolumn{2}{l}{ Fungal } & & \multicolumn{2}{l}{ Bacterial } \\
\cline { 2 - 3 } \cline { 5 - 6 } & $P$ & $\mathrm{R}^{2}$ & & $P$ & $\mathrm{R}^{2}$ \\
\hline SM vs WS & $0.01^{* *}$ & 0.24 & & $0.01^{* *}$ & 0.31 \\
SM vs CT & $0.01^{* *}$ & 0.26 & & $0.01^{* *}$ & 0.30 \\
WS vs CT & $0.01^{* *}$ & 0.31 & & 0.1 & 0.12 \\
\hline
\end{tabular}

(Fig. 2).

Ascomycota and Basidiomycota were the dominant fungal phyla in all three type sediments, representing $70.3 \%-83.1 \%$ and $5.5 \%-17.3 \%$ of classified OTUs, respectively (Fig. 2). The dominant classes across all samples were Dothideomycetes and Sordariomycetes (phylum Ascomycota). Tremellomycetes were significantly higher in the crab bioturbated sediment than the non-bioturbated sediment. In contrast, the relative abundance of Agaricomycetes was significantly higher in the mound sediments than in the other sediments (Fig. 2).
Significant differences were noted in the bacterial $\beta$-diversity, as assessed by mass, among the three type samples (Fig. $3, P<0.01$ ). The fungal communities differed significantly between mound and wall or control sediments $(P<0.01$, Table 1$)$.

\subsection{Co-occurrence network analysis}

Network analyses based on Spearman's correlations revealed some effects of crab bioturbation on microbial interactions (Fig. 4). Networks were separately generated for bacteria and fungi in each sediment type, and topological properties were determined to characterize each network (Table 2). Results showed that crab bioturbation changed not only the community composition of fungi and bacteria, but also the relationships among microbes. The average degree of interaction was higher in the bacterial network than that in the fungal network. The modularity of bacterial and fungal networks, except the bacterial network in wall sediments, was greater than 0.4 , indicating a modular structure. The modularity of soil fungal networks decreased after crab bioturbations. The clustering coefficient of networks was higher in crab bioturbated sediments (SM and WS) than in non-bioturbated sediments.

\subsection{Responses of microbial functional structure to crab bioturbation}

Bacterial functions were predicted according to the FAPROTAX database. The 30 functional groups with the highest relative abundances were considered. The main bacterial functional groups among the three type samples were chemoheterotrophy, aerobic chemoheterotrophy, fermentation, respiration of sulfur compounds, sulfur respiration, thiosulfate respiration, hydrocarbon degradation, and nitrate reduction (Fig. 5). Among these 30 functional groups, chemoheterotrophy and bacterial aerobic chemoheterotrophy showed significant differences among the three types of soil samples, with the relative abundances of chemoheterotrophic and aerobic chemoheterotrophic bacteria being significantly higher in wall than control sediments.

The soil fungi were mainly divided into four functional types - saprotrophs, pathotrophs, symbiotrophs, and pathotroph-saprotrophs based on the fungal trophic mode (Fig. 6). The crab burrows had a significant effect on the pathotrophic and symbiotrophic fungi. The relative abundance of saprotrophs was significantly lower in mound than in wall or control sediments $(P<0.05)$, with a reduction by $71.6 \%$ and $57.6 \%$, respectively. Pathotroph-saprotroph types were less abundant in mound than in control sediments $(P<0.05)$.

\section{Discussion}

\subsection{Bacterial and fungal taxonomic shifts}

Diversity among bacteria was highest in mound sediment while fungal diversity was highest in control sediments. Fungi tend to decompose more recalcitrant compounds and are regarded as $K$ selected, while bacteria decompose labile compounds and are regarded as $r$-selected (Paul, 2007). In this study, the mound soil was suitable for the growth of $r$-selected microbes, while the control soil was more suitable for the growth of $K$-selected. Compared with the control soils, the diversity of fungi in the bioturbated mound and burrow wall soils was reduced, consistent with the results of Booth et al. (2019). On the other hand, the reduced fungal diversity in crab bioturbated sediments might be due to the fact that crab activity destroys the hyphal networks in the burrows, and that the crabs may compete with fungi for food. Additionally, crabs may feed on fungi directly (Kristensen et al., 2010). Studies had shown that the diversity and structure of microbial communities are linked with ecosystem function (Graham et al., 2016). Microbial diversity enhances multiple ecosystem functions, and a loss in soil biodiversity threatens ecosystem functioning (Wagg et al., 2014, 2019). Therefore, a decrease of fungal diversity could have negative effects on ecological functions. 
(a)

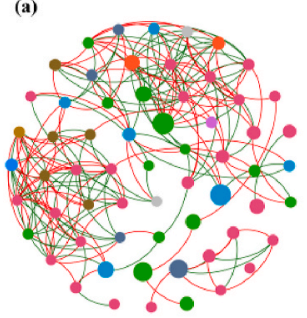

(d)

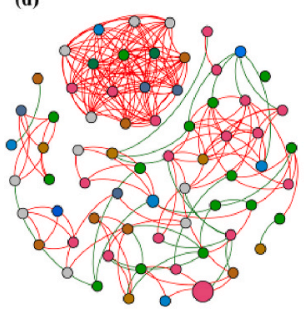

(b)

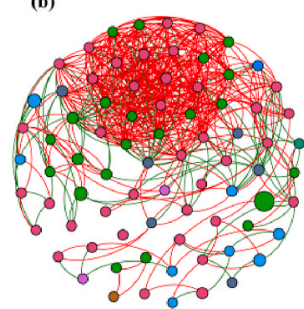

(e)

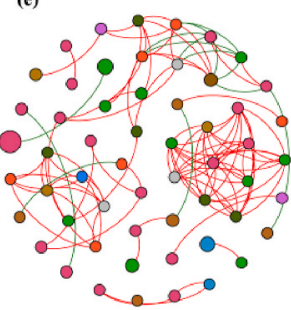

(c)
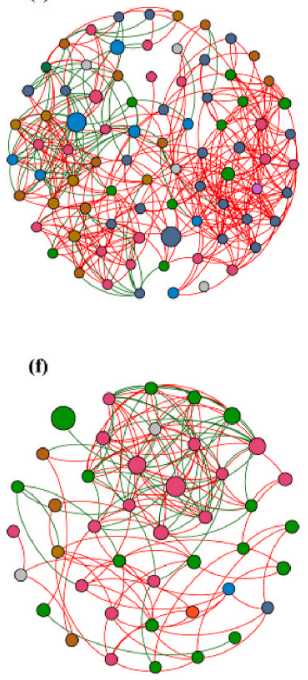

- Proteobacteria

- Bacteroidetes

- Firmicutes

- Chloroflexi

- Actinobacteria

- Gemmatinonadete

- Acidobacteria

- Halanaeroiaeota

- Epsilonbacteriaota

- Deinococcus-Thermus

Others

Fig. 4. Interactions of bacteria (a, b, c) and fungi (d, e, f) in the soil mound sediment (a, d); burrow wall sediment (b, e); and no-bioturbated sediment (c, f) with crabs. The line between each pair of nodes represents strong positive (red) or negative (green) interactions with adjusted $P<0.05$ and absolute correlation values $>$ 0.8 . Only relative abundances $>0.2 \%$ bacterial ( $a, b$ and $c$ ) or fungal (c, $d$ and f) OTUs were included in the analysis. (For interpretation of the references to colour in this figure legend, the reader is referred to the Web version of this article.)

Table 2

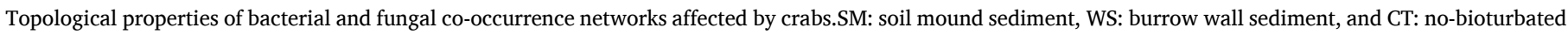
sediment.

\begin{tabular}{|c|c|c|c|c|c|c|c|}
\hline & Sample & Node & Edges & Average degree & Clustering coefficient & Modularity & Average diameter \\
\hline \multirow[t]{3}{*}{ Bacterial } & CT & 82 & 415 & 10.122 & 0.587 & 0.531 & 7 \\
\hline & WS & 79 & 544 & 13.772 & 0.684 & 0.362 & 9 \\
\hline & SM & 62 & 219 & 7.065 & 0.658 & 0.583 & 10 \\
\hline \multirow[t]{3}{*}{ Fungal } & СT & 43 & 154 & 7.163 & 0.525 & 1.692 & 8 \\
\hline & WS & 56 & 111 & 3.964 & 0.728 & 0.665 & 5 \\
\hline & SM & 68 & 214 & 6.294 & 0.732 & 0.494 & 12 \\
\hline
\end{tabular}

We showed that the relative abundances of Proteobacteria and Bacteroidetes were significantly increased, while Actinobacteria were significantly decreased after crab bioturbations. Actinobacteria exhibit slow growth rates even when resources are abundant, but they are able to degrade recalcitrant lignin and cellulose, to produce polyphenolic compounds (Pankratov et al., 2011; Eisenlord et al., 2013). Crab feeding behavior of physical scrapping and their digestion of organic matter provides labile substrates for copiotrophic groups, which is beneficial to their growth and metabolism (Kristensen and Pilgaard, 2001). The change in bacterial community structure indicated that the composition of the bacterial community had changed from an oligotrophic group to a copiotrophic group, and thus overall bacterial community degradation ability was decreased following crab bioturbation.

\subsection{Crabs impact soil microbial networks}

Complex ecological networks typically increase the stability of food webs and ecosystems (Neutel et al., 2007; Zelezniak et al., 2015). Our results showed that both the co-occurrence networks and degree of connectivity were altered by crab bioturbation. Different patterns in the co-occurrence networks occurred for bacteria and fungi, as also noted by Xiao et al. (2018).

Crab burrows create new microhabitats, thereby changing the physicochemical properties of organic matter; these different environmental conditions are likely the major drivers of microbial communities and co-occurrence network variations among soils (Smith et al., 2014). Helice tientsinensis crabs are omnivores that mainly live on coastal wetland plants, microalgae, and sediments (He and Silliman, 2016).
When crabs ingest sediments in the burrows, they also digest and absorb organic matter and microbes from the sediments (Skov and Hartnoll, 2002). This could directly reduce microbial biomass. On the other hand, both crabs and fungi contribute to the decomposition of plant litter, so there is likely food resource competition between the two organisms. Zelezniak et al. (2015) found that metabolic dependence is a major driver of species co-occurrence. As a result, co-occurrence groups can be mutually beneficial, as different species can more efficiently utilize limited resources and coexist across various niches. The habitat changes caused by crab bioturbation limit the survival of fungi; however, the utilization efficiency of resources can also be improved by a greater number of species connections (Morrien et al., 2017). The high modularity of their networks reflects that biological interactions are more frequent within the modules than outside the modules (Chagnon et al., 2012). Studies have shown that modularity of networks has a negative relationship with a community's ability to adapt to changes in biotic or abiotic factors (Eldridge et al., 2015). Because the modularity of fungal networks decreased after crab bioturbation, which may improve tolerance and resilience from environmental and resource changes.

Our results suggested that whether or not they are disturbed by crabs, bacteria tend to have more connections than fungi. This difference may result because bacterial diversity is higher than fungal diversity, and generally grow faster than fungi (Rousk and Båăth, 2011). Nevertheless, more connections don't necessarily mean that bacteria are more important than fungi. Other studies have demonstrated that the changes in fungi in intertidal sediments have synergistic effects on the development of both microbial communities and their function (Booth et al., 2019). Collectively, bacteria and fungi may play complementary roles in 


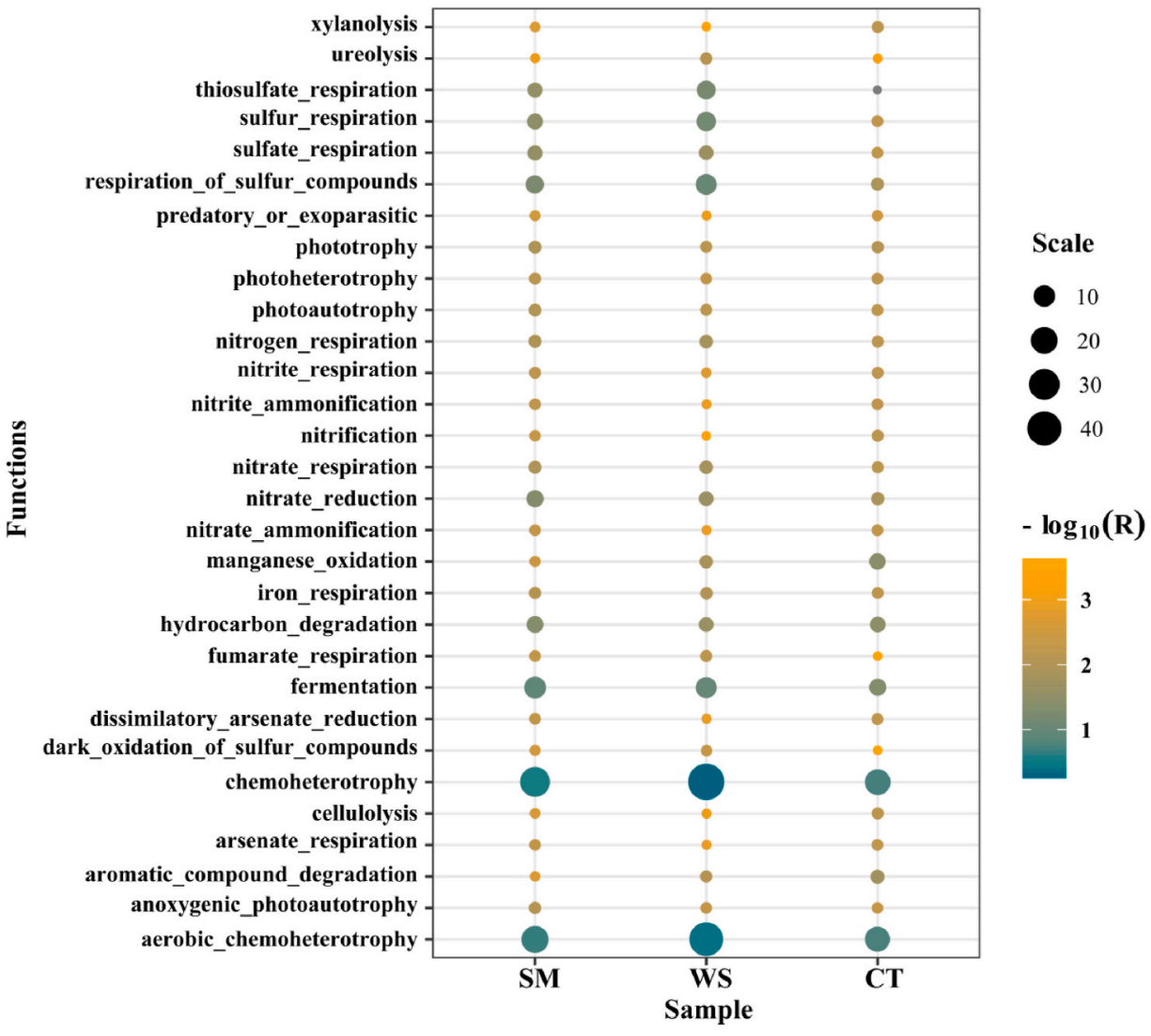

Fig. 5. Main functional structure of soil bacteria in the soil mound sediment (SM), burrow wall sediment (WS), and no-bioturbated sediment (CT).
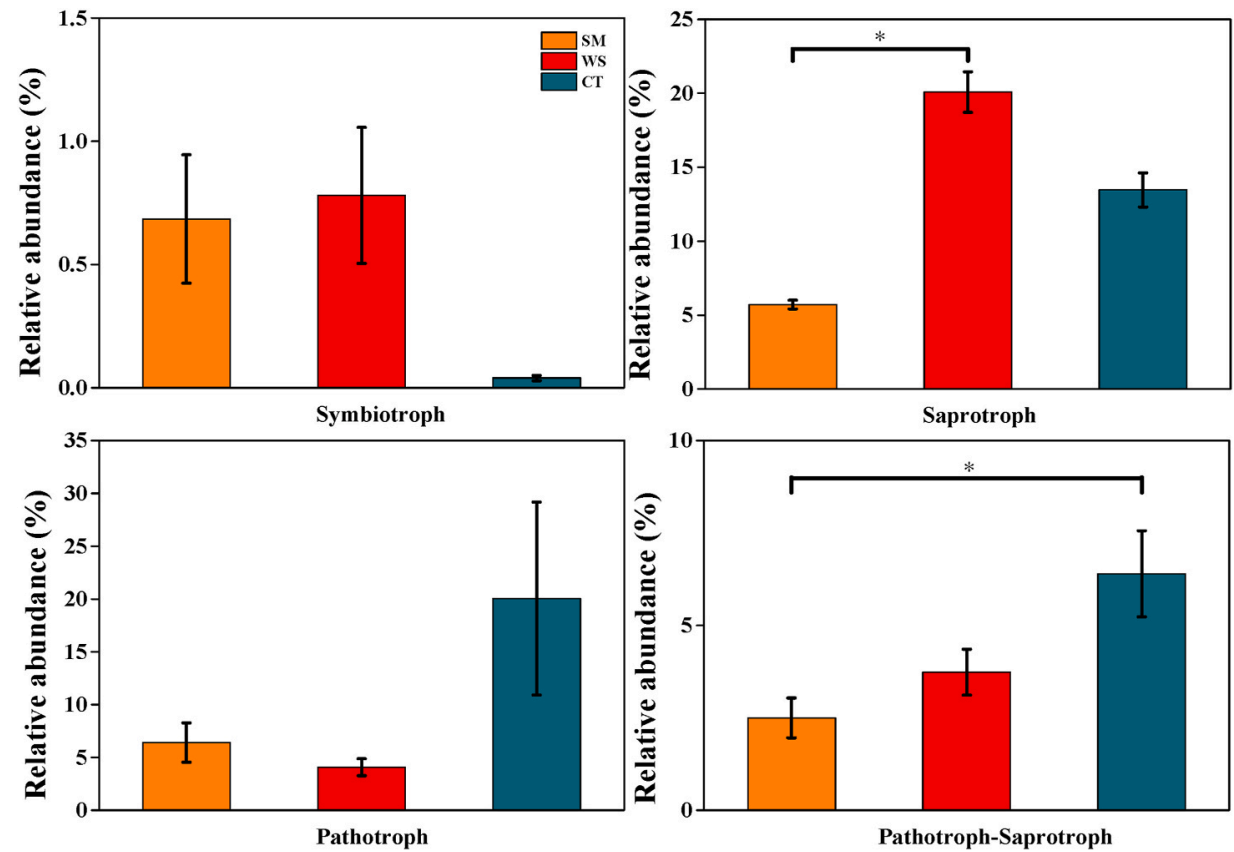

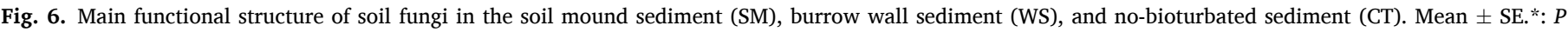
$<0.05$.

various habitats.

\subsection{Crabs and soil microbial functions}

The most abundant microbial function in all three soil types was chemoheterotrophy. This was not surprising, as most bacteria are chemoheterotrophs. Furthermore, the chemoheterotrophy and bacterial aerobic chemoheterotrophy in the burrow wall soils were significantly higher than those in the control soils. The increase in the relative abundance of chemoheterotrophy and aerobic chemoheterotrophy 
induced by bioturbation is likely due to $\mathrm{O}_{2}$ injection and the increased bioavailability of sedimentary organic matter. A recent investigation reported a $\mathrm{CO}_{2}$ flux increment of $200 \%$ after bioturbation in a mudflat, and an increment of $8000 \%$ in a salt marsh (Fanjul et al., 2015). Thus, the increase in relative abundance of chemoheterotrophy and aerobic chemoheterotrophy may have increased levels of $\mathrm{CO}_{2}$ flux.

Fungal communities are highly diverse, both taxonomically and functionally, and fungal communities likely control the rates of key ecosystem processes and directly affect the community structure of plants and animals, through either pathogenic or mutualistic interactions (Anderson and Cairney, 2004; Falkowski et al., 2008; Peay et al., 2008; Gessner et al., 2010). In our study, significant differences were noted in fungal functions between the control and mound soils (Fig. 6). After crab burrows were formed, the relative abundance of pathotrophic-saprotrophic and saprotrophic fungi in the mound soils was significantly decreased, as compared with the control soils (Fig. 6).

Saprotrophic fungi play an important role in the decomposition of organic matter and nutrient cycling in forest soils (Talbot et al., 2014). Saprotrophs can compete with ectomycorrhizal fungi for soil nitrogen (Fernandez and Kennedy, 2015). A reduction in the relative abundance of saprotrophic fungi may lead to reduced decomposition and increased sequestration of available carbon (Gadgil and Gadgil, 1971; Gadgil, 1975; Fernandez and Kennedy, 2015). Lenhart et al. (2012) reported that saprotrophic fungi are drivers of methane production. Therefore, a reduction in the relative abundance of saprotrophic fungi may reduce methane emissions. A reduction in the corresponding functional fungal abundance can thus have different effects on various plants. Pathological vegetative fungi in soil can have negative effects (Anthony et al., 2017). Therefore, compared with the non-bioturbated control soils, the reduced relative abundance of pathotrophic-saprotrophic fungi in bioturbated soils may have a positive effect on plants.

\section{Conclusion}

Our findings suggest that crab bioturbation likely alters both the bacterial and fungal communities in intertidal wetland soils, and affects the interaction patterns among microbial taxa. The composition of bacterial communities changed from an oligotrophic group to a copiotrophic group. The fungal community had increased connections between internal communities in response to crab bioturbation. Functional predictions of fungi and bacteria indicated that crab bioturbations decrease the relative abundance of pathotrophic-saprotrophic and saprotrophic fungi in the mound sediments, while increasing the dominance of chemoheterotrophy and aerobic chemoheterotrophy. Consequently, our results indicate that crab bioturbations change the roles of microbes in nutrient cycles, and should be considered when studying ecosystem functions of coastal wetlands.

\section{CRediT authorship contribution statement}

Chuanjing Wu: Writing - original draft, Formal analysis, Data curation. Haitao Wu: Supervision, Conceptualization, Methodology, Project administration. Dandan Liu: Data curation, Formal analysis. Guangxuan Han: Writing - review \& editing, Resources. Panpan Zhao: Formal analysis, Visualization. Yujuan Kang: Data curation, Formal analysis, Visualization.

\section{Declaration of competing interest}

The authors declare that they have no known competing financial interests or personal relationships that could have appeared to influence the work reported in this paper.

\section{Acknowledgements}

The study was supported by the programs of the National Key
Research and Development Project of China (Project 2017YFC0505901), and National Natural Science Foundation of China (Project 41871099 and 41671260), and the Science and Technology Development Program of Jilin Province (20180101080JC). The staff of the Yellow River Delta National Natural Reserve provided support.

\section{References}

Abarenkov, K., Nilsson, R.H., Larsson, K.H., Alexander, I.J., Eberhardt, U., Erland, S., Høiland, K., Kjøller, R., Larsson, E., Pennanen, T., 2010. The UNITE database for molecular identification of fungi - recent updates and future perspectives. New Phytol. 186, 281-285.

Anderson, I.C., Cairney, J.W.G., 2004. Diversity and ecology of soil fungal communities: increased understanding through the application of molecular techniques. Environ. Microbiol. 6, 769-779.

Anthony, M.A., Frey, S.D., Stinson, K.A., 2017. Fungal community homogenization, shift in dominant trophic guild, and appearance of novel taxa with biotic invasion. Ecosphere (Berkeley) 1-17.

Bates, S.T., Clemente, J.C., Flores, G.E., Walters, W.A., Parfrey, L.W., Knight, R., Fierer, N., 2013. Global biogeography of highly diverse protistan communities in soil. ISME J. 7, 652-659.

Bertrand, M., Barot, S., Blouin, M., Whalen, J., de Oliveira, T., Roger, E.J., 2015. Earthworm services for cropping systems. A review. Agron. Sustain. Dev. 35, $553-567$.

Booth, M.J., Fusi, M., Marasco, R., Michoud, G., Fodelianakis, S., Merlino, G., Daffonchio, D., 2019. The role of fungi in heterogeneous sediment microbial networks. Sci. Rep. 9, 7537.

Chagnon, P.L., Bradley, R.L., Klironomos, J.N., 2012. Using ecological network theory to evaluate the causes and consequences of arbuscular mycorrhizal community structure. New Phytol. 194, 307-312.

Courty, P.-E., Buée, M., Diedhiou, A.G., Frey-Klett, P., Le Tacon, F., Rineau, F., Turpault, M.P., Uroz, S., Garbaye, J., 2010. The role of ectomycorrhizal communities in forest ecosystem processes: new perspectives and emerging concepts. Soil Biol. Biochem. 42, 679-698.

Delgado-Baquerizo, M., Maestre, F.T., Reich, P.B., Trivedi, P., Osanai, Y., Liu, Y.R., Hamonts, K., Jeffries, T.C., Singh, B.K., 2016. Carbon content and climate variability drive global soil bacterial diversity patterns. Ecol. Monogr. 86, 373-390.

DerksenH, M., van der, Heide, T., Lamers, L.P.M., Borst, A., Smolders, A.J.P., GoversL, L., HoogveldJ, R.H., AngeliniChristine, 2019. Burrowing crabs weaken mutualism between foundation species. Ecosystems 22, 767-780.

Eisenlord, S.D., Freedman, Z., Zak, D.R., Xue, K., He, Z., Zhou, J., 2013. Microbial mechanisms mediating increased soil C storage under elevated atmospheric N deposition. Appl. Environ. Microbiol. 79, 1191-1199.

Eldridge, D.J., Woodhouse, J.N., Curlevski, N.J., Hayward, M., Brown, M.V., Neilan, B. A., 2015. Soil-foraging animals alter the composition and co-occurrence of microbial communities in a desert shrubland. ISME J. 9, 2671-2681.

Falkowski, P.G., Fenchel, T., Delong, E.F., 2008. The microbial engines that drive earth's biogeochemical cycles. Science 320, 1034-1039.

Fanjul, E., Escapa, M., Montemayor, D., Addino, M., Alvarez, M.F., Grela, M.A., Iribarne, O., 2015. Effect of crab bioturbation on organic matter processing in South West Atlantic intertidal sediments. J. Sea Res. 95, 206-216.

Fernandez, C.W., Kennedy, P.G., 2015. Revisiting the 'Gadgil effect': do interguild fungal interactions control carbon cycling in forest soils? New Phytol. 209, 1382-1394.

Ferreira, T.O., Otero, X.L., Vidal-Torrado, P., Macías, F., 2007. Effects of bioturbation by root and crab activity on iron and sulfur biogeochemistry in mangrove substrate. Geoderma 142, 0-46.

Gadgil, R.L., Gadgil, P.D., 1971. Mycorrhiza and litter decomposition. Nature 233, 133.

Gadgil, R.L., Gadgil, P.D., 1975. Suppression of litter decomposition by mycorrhizal roots of Pinus radiata. N. Z. J. For. Sci. 5, 8.

Gessner, M.O., Swan, C.M., Dang, C.K., McKie, B.G., Bardgett, R.D., Wall, D.H., Hattenschwiler, S., 2010. Diversity meets decomposition. Trends Ecol. Evol. 25, 372-380.

Gillis, L.G., Snavely, E., Lovelock, C., Zimmer, M., 2019. Effects of crab burrows on sediment characteristics in a Ceriops australis-dominated mangrove forest. Estuar. Coast Shelf Sci. 218, 334-339.

Graham, E.B., Knelman, J.E., Schindlbacher, A., Siciliano, S., Breulmann, M., Yannarell, A., Beman, J.M., Abell, G., Philippot, L., Prosser, J., Foulquier, A., Yuste, J.C., Glanville, H.C., Jones, D.L., Angel, R., Salminen, J., Newton, R.J., Burgmann, H., Ingram, L.J., Hamer, U., Siljanen, H.M., Peltoniemi, K., Potthast, K., Baneras, L., Hartmann, M., Banerjee, S., Yu, R.Q., Nogaro, G., Richter, A., Koranda, M., Castle, S.C., Goberna, M., Song, B., Chatterjee, A., Nunes, O.C., Lopes, A.R., Cao, Y., Kaisermann, A., Hallin, S., Strickland, M.S., Garcia-Pausas, J., Barba, J., Kang, H., Isobe, K., Papaspyrou, S., Pastorelli, R., Lagomarsino, A., Lindstrom, E.S., Basiliko, N., Nemergut, D.R., 2016. Microbes as engines of ecosystem function: when does community structure enhance predictions of ecosystem processes? Front. Microbiol. 7, 214.

Guo, X., Feng, J., Shi, Z., Zhou, X., Yuan, M., Tao, X., Hale, L., Yuan, T., Wang, J., Qin, Y., Zhou, A., Fu, Y., Wu, L., He, Z., Van Nostrand, J.D., Ning, D., Liu, X., Luo, Y. Tiedje, J.M., Yang, Y., Zhou, J., 2018. Climate warming leads to divergent succession of grassland microbial communities. Nat. Clim. change 8 813-818.

Gutiérrez, J.L., Jones, C.G., Ribeiro, P.D., Findlay, S.E.G., Groffman, P.M., 2018. Crab burrowing limits surface litter accumulation in a temperate salt marsh: implications for ecosystem functioning and connectivity. Ecosystems 21, 1000-1012. 
He, Q., Silliman, B.R., 2016. Consumer control as a common driver of coastal vegetation worldwide. Ecol. Monogr. 86, 278-294.

Hu, Z., Wu, S., Ji, C., Zou, J., Zhou, Q., Liu, S., 2015. A comparison of methane emissions following rice paddies conversion to crab-fish farming wetlands in southeast China. Environ. Sci. Pollut. Res. 23, 1505-1515.

Kristensen, E., 2008. Mangrove crabs as ecosystem engineers; with emphasis on sediment processes. J. Sea Res. 59, 30-43.

Kristensen, E., Pilgaard, R., 2001. The role of fecal pellet deposition by leaf-eating sesarmid crabs on mineralization processes in a mangrove sediment (Phuket, Thailand). In: Aller, J.Y., Woodin, S.A., Aller, R.C. (Eds.), Organism-Sediment Interactions. University of South Carolina Press, Columbia, pp. 369-384.

Kristensen, D.K., Kristensen, E., Mangion, P., 2010. Food partitioning of leaf-eating mangrove crabs (Sesarminae): experimental and stable isotope $\left({ }^{13} \mathrm{C}\right.$ and $\left.{ }^{15} \mathrm{~N}\right)$ evidence. Estuar. Coast Shelf Sci. 87, 583-590.

Lenhart, K., Bunge, M., Ratering, S., Neu, T.R., Schuttmann, I., Greule, M., Kammann, C. Schnell, S., Muller, C., Zorn, H., Keppler, F., 2012. Evidence for methane production by saprotrophic fungi. Nat. Commun. 3, 1046.

Lohrer, A.M., Thrush, S.F., Gibbs, M.M., 2004. Bioturbators Enhance Ecosystem Function through Complex Biogeochemical Interactions. Nature431, pp. 1092-1095.

Louca, S., Parfrey, L.W., Doebeli, M., 2016. Decoupling function and taxonomy in the global ocean microbiome. Science 353, 1272-1277.

Luo, L., Gu, J.D., 2018. Influence of macro faunal burrows on extracellular enzyme activity and microbial abundance in subtropical mangrove sediment. Microb. Ecol. 76, 92-101.

Magoc, T., Salzberg, S.L., 2011. FLASH: fast length adjustment of short reads to improve genome assemblies. Bioinformatics 27, 2957-2963.

Morrien, E., Hannula, S.E., Snoek, L.B., Helmsing, N.R., Zweers, H., de Hollander, M., Soto, R.L., Bouffaud, M.L., Buee, M., Dimmers, W., Duyts, H., Geisen, S., Girlanda, M., Griffiths, R.I., Jorgensen, H.B., Jensen, J., Plassart, P., Redecker, D., Schmelz, R.M., Schmidt, O., Thomson, B.C., Tisserant, E., Uroz, S., Winding, A., Bailey, M.J., Bonkowski, M., Faber, J.H., Martin, F., Lemanceau, P., de Boer, W., van Veen, J.A., van der Putten, W.H., 2017. Soil networks become more connected and take up more carbon as nature restoration progresses. Nat. Commun. 8, 14349.

Myers, R.T., Zak, D.R., White, D.C., Peacock, A., 2001. Landscape-level patterns of microbial community composition and substrate use in upland forest ecosystems. Soil Sci. Soc. Am. J. 65, 359.

Neutel, A.M., Heesterbeek, J.A., van de Koppel, J., Hoenderboom, G., Vos, A., Kaldeway, C., Berendse, F., de Ruiter, P.C., 2007. Reconciling complexity with stability in naturally assembling food webs. Nature 449, 599-602.

Nguyen, N.H., Song, Z., Bates, S.T., Branco, S., Tedersoo, L., Menke, J., Schilling, J.S., Kennedy, P.G., 2016. FUNGuild: an open annotation tool for parsing fungal community datasets by ecological guild. Fungal Ecol 20, 241-248.

Ochoa-Hueso, R., Collins, S.L., Delgado-Baquerizo, M., Hamonts, K., Pockman, W.T., Sinsabaugh, R.L., Smith, M.D., Knapp, A.K., Power, S.A., 2018. Drought consistently alters the composition of soil fungal and bacterial communities in grasslands from two continents. Global Change Biol. 24, 2818-2827.

Pankratov, T.A., Ivanova, A.O., Dedysh, S.N., Liesack, W., 2011. Bacterial populations and environmental factors controlling cellulose degradation in an acidic Sphagnum peat. Environ. Microbiol. 13, 1800-1814.

Paul, E.A., 2007. Soil Microbiology, Ecology and Biochemistry, third ed. Academic Press, San Diego.

Peay, K.G., Kennedy, P.G., Bruns, T.D., 2008. Fungal community ecology: a hybrid beast with a molecular master. Bioscience 58, 799-810.
Quast, C., Pruesse, E., Yilmaz, P., Gerken, J., Schweer, T., Yarza, P., Peplies, J., Glockner, F.O., 2013. The SILVA ribosomal RNA gene database project: improved data processing and web-based tools. Nucleic Acids Res. 41, 590-596.

R Robertson, A.I., Daniel, P.A., 1989. The influence of crabs on litter processing in high intertidal mangrove forests in tropical Australia. Oecologia 78, 191-198.

Rousk, J., Bååth, E., 2011. Growth of saprotrophic fungi and bacteria in soil. FEMS Microbiol. Ecol. 78, 17-30.

Rousk, J., Bååth, E., Brookes, P., Brookes, P.C., Lauber, C.L., Lozupone, C., Caporaso, J. G., R Knight, R., Fierer, N., 2010. Soil bacterial and fungal communities across a pH gradient in an arable soil. ISME J. 4, 1340-1351.

Skov, M.W., Hartnoll, R.G., 2002. Paradoxical selective feeding on a low-nutrient diet: why do mangrove crabs eat leaves? Oecologia 131, 1-7.

Smith, A.P., Marín-Spiotta, E., de Graaff, M.A., Balser, T.C., 2014. Microbial community structure varies across soil organic matter aggregate pools during tropical land cover change. Soil Biol. Biochem. 77, 292-303.

Stahl, M.O., Tarek, M.H., Yeo, D.C.J., Badruzzaman, A.B.M., Harvey, C.F., 2014. Crab burrows as conduits for groundwater-surface water exchange in Bangladesh. Geophys. Res. Lett. 41, 8342-8347.

Talbot, J.M., Bruns, T.D., Taylor, J.W., Smith, D.P., Branco, S., Glassman, S.I., Erlandson, S., Vilgalys, R., Liao, H.L., Smith, M.E., Peay, K.G., 2014. Endemism and functional convergence across the North American soil mycobiome. P. Natl. Acad. Sci. USA 111, 6341-6346.

Wagg, C., Bender, S.F., Widmer, F., van der Heijden, M.G., 2014. Soil biodiversity and soil community composition determine ecosystem multifunctionality. P. Natl. Acad. Sci. USA 111, 5266-5270.

Wagg, C., Schlaeppi, K., Banerjee, S., Kuramae, E.E., van der Heijden, M.G.A., 2019. Fungal-bacterial diversity and microbiome complexity predict ecosystem functioning. Nat. Commun. 10, 4841.

Wang, J.Q., Zhang, X.D., Jiang, L.F., Bertness, M.D., Fang, C.M., Chen, J.K., Hara, T., $\mathrm{Li}$, B., 2010. Bioturbation of burrowing crabs promotes sediment turnover and carbon and nitrogen movements in an estuarine salt marsh. Ecosystems 13, 586-599.

Wieltschnig, C., Fischer, U.R., Velimirov, B., Kirschner, A.K., 2008. Effects of depositfeeding macrofauna on benthic bacteria, viruses, and protozoa in a silty freshwater sediment. Microb. Ecol. 56, 1-12.

Wolters, V., 2000. Invertebrate control of soil organic matter stability. Biol. Fertil. Soils 31, 1-19.

Wu, H., Batzer, D.P., Yan, X., Lu, X., Wu, D., 2013. Contributions of ant mounds to soil carbon and nitrogen pools in a marsh wetland of Northeastern China. Appl. Soil Ecol. 70, 9-15.

Wu, H., Lu, M., Lu, X., Guan, Q., He, X., 2015a. Interactions between earthworms and mesofauna has no significant effect on emissions of $\mathrm{CO}_{2}$ and $\mathrm{N}_{2} \mathrm{O}$ from soil. Soil Biol. Biochem. 88, 294-297.

Wu, H., Lu, X., Tong, S., Batzer, D.P., 2015b. Soil engineering ants increase $\mathrm{CO}_{2}$ and $\mathrm{N}_{2} \mathrm{O}$ emissionsby affecting mound soil physicochemical characteristics from a marsh soil: a laboratory study. Appl. Soil Ecol. 87, 19-26.

Xiao, X., Liang, Y., Zhou, S., Zhuang, S., Sun, B., 2018. Fungal community reveals less dispersal limitation and potentially more connected network than that of bacteria in bamboo forest soils. Mol. Ecol. 27, 550-563.

Xiao, K., Wilson, A.M., Li, H., Ryan, C., 2019. Crab burrows as preferential flow conduits for groundwater flow and transport in salt marshes: a modeling study. Adv. Water Resour. 132, 103408.

Zelezniak, A., Andrejev, S., Ponomarova, O., Mende, D.R., Bork, P., Patil, K.R., 2015. Metabolic dependencies drive species co-occurrence in diverse microbial communities. P. Natl. Acad. Sci. USA 112, 6449-6454. 